of alcoholic drinks per week, smoking status and Rapid Assessment of Physical Activity (RAPA)). Univariable ordinal logistic regression tested the relationship between pain and waking unrefreshed. The model was then cumulatively adjusted for sleep, somatic symptoms, mental health, disability and lifestyle domains. All models were age, sex and deprivation adjusted. The results of a complete case analysis were comparable to those which used multiple imputation for missing data and the results of the complete case analyses are shown. Results were expressed as odds ratios (OR) with $95 \%$ confidence intervals $(\mathrm{Cl})$.

Results: Of 1913 people who had complete data, $1376(72 \%)$ woke unrefreshed on at least one day in the past month $(41 \% 1-7$ days; $31 \%>8$ days). Compared to those with no pain, people with acute pain and chronic pain were two (OR $2.0,95 \% \mathrm{Cl}(1.5-2.6)$ and $2.2(1.9-2.7)$, respectively) times more likely to wake unrefreshed; those with CWP were five (5.0 (4.0-6.3)), times more likely to wake unrefreshed. Following adjustment for all other variables, the relationship between reporting chronic pain (1.5 (1.2-1.8)) or CWP (1.9 (1.4-1.5)) and waking unrefreshed was attenuated, but remained statistically significant. The reporting of acute pain was not an independent predictor of waking unrefreshed (1.4 (0.981.9)). Problems with sleep onset ( $>8$ days vs $0: 2.9(2.0-4.1)$ ) and maintenance ( $\geq 8$ days vs $0: 5.9(4.1-8.4)$ ), night awakenings ( $\geq 8$ days vs $0: 2.5$ (1.7-3.7)), IBS (2.2 (1.2-4.0)), currently smoking (vs never: $1.5(1.02-2.1))$ and engagement in activities such as stretching and yoga (vs none: $0.8(0.6-0.97))$, physical $(1.3$ (1.2-1.3)) but not mental $(0.99(0.9-1.1))$ fatigue, and anxiety (definite vs no: 2.4 $(1.8-3.1)$ ), but not depression (definite vs no: $1.5(0.8-2.6)$ ), were associated with waking unrefreshed.

Conclusions: This study suggests that among people with chronic pain, the risk of waking feeling unrefreshed may be reduced through interventions that target factors such as smoking cessation, IBS management, physical fatigue and anxiety.

Acknowledgements: J. Anderson, M. Mulvey, A. Rashid

Disclosure of Interest: None declared

DOI: 10.1136/annrheumdis-2017-eular.1798

\section{FRI0713 LOW BONE MINERAL DENSITY IS THE MAIN CONTRIBUTOR TO FALLS-RELATED HEALTH BURDEN IN THE EUROPEAN ELDERLY}

L. Sanchez-Riera ${ }^{1}$, N. Wilson ${ }^{2}$, D. Prieto-Alhambra ${ }^{3}$, C. Cooper ${ }^{4}$, K. Dreinhöfer ${ }^{5}$, A. Woolf ${ }^{6}$, L. March ${ }^{2}$, P. Halbout ${ }^{7} .{ }^{1}$ University Hospital Bristol NHS Foundation Trust, Bristol, United Kingdom; ${ }^{2}$ Institute of Bone and Joint Research, University of Sydney, Sydney, Australia; ${ }^{3}$ Oxford NIHR Musculoskeletal Biomedical Research Unit, University of Oxford, Oxford; ${ }^{4}$ MRC Lifecourse Epidemiology Unit, University of Southampton, Southampton, United Kingdom; ${ }^{5}$ Center for Musculoskeletal Surgery, Charité Universitätsmedizin, Berlin, Germany; ${ }^{6}$ Institute of Health Research, University of Exeter Medical School, Exeter, United Kingdom; ${ }^{7}$ International Osteoporosis Foundation, Nyon, Switzerland

Background: Falls are the leading injury type in elderly populations and a major health burden and cause of death globally. Most of such burden is due to bone fractures. In the Global Burden of Diseases (GBD) Initiative, the attributable burden of falls due to low bone mineral density (BMD) was analysed through its relationship with fractures.

Objectives: To measure the percentage of disability-adjusted life years (DALYs), years lived with disability (YLDs) and deaths due to falls attributable to low BMD in European population for the year 2015.

Methods: The estimates followed the Counterfactual Risk Assessment Methodology used in the GBD study (1). Systematic review was performed seeking population-based studies with femoral neck (FNBMD) measured by Dual-X-RayAbsorptiometry in people 50 years and over. Age- and sex- specific levels of mean +/-SD FNBMD $\left(\mathrm{g} / \mathrm{cm}^{2}\right)$ were extracted from eligible studies, and this was used as the exposure variable. The age and sex-specific 99th percentile from non-Hispanic whites in the National Health and Nutrition Examination Survey (NHANES) 2009-2010 was used as theoretical minimum risk factor exposure distribution, to estimate the potential impact fraction (PIF) of FNBMD for fractures. Relative risks of FNBMD for fractures were obtained from a previous meta-analysis (2). Coded hospital data was used to calculate the fraction of falls-related deaths due to fractures. Disability levels were established by applying disability weights

Percentage of Deaths, DALYs and YLDs of Falls, Attributable to Low BMD in Europe

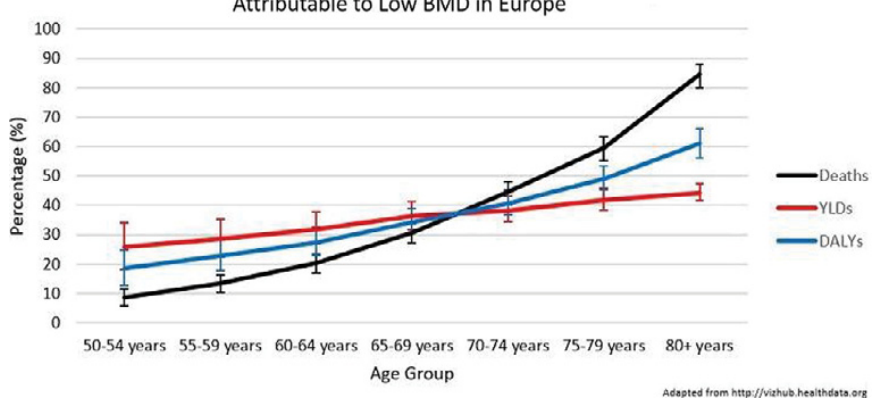

to each type of fracture. Then, PIFs were applied to obtain attributable deaths and disability due to low BMD.

Results: The percentage of falls-related preventable deaths attributable to low BMD is around $9 \%$ in the $50-54$ age group, increasing to $84 \%$ in those aged 80 years and over. Total health burden (DALYs) and disability attribution (YLDs) also increase with age, from $19 \%$ and $25 \%$ in $50-54$ years old, respectively, to $61 \%$ and $44 \%$ and population aged 80 years and above, respectively. Low BMD constitutes the most important preventable risk factors for falls-related DALYs from 50 years and above, followed by alcohol, occupational risk and smoking.

Conclusions: Low BMD is a major preventable risk factor that explains a very remarkable proportion of falls health burden in Europe, in particular in those aged 70 years and above. This is a growing concern, given the population trajectories, and requires urgent attention.

References:

[1] Forouzanfar $\mathrm{M}$ et al, Lancet 2016.

[2] Johnell O et al, JBMR 2015.

Disclosure of Interest: None declared

DOI: 10.1136/annrheumdis-2017-eular.6616

\section{FRI0714 LUPUS NEPHRITIS AND PROGNOSIS. EFFECT OF MEMBRANOUS AND OTHER COMPONENTS OF THE HISTOLOGY}

M.U. Martinez Martinez ${ }^{1}$, C. Vallín-Orozco ${ }^{1}$, H.E. Esparza-Holguin ${ }^{1}$, G. Aguilera-Barragán Pickens ${ }^{1}$, D. Martínez-Galla ${ }^{2}$, C. Abud-Mendoza ${ }^{1}$.

${ }^{1}$ Unidad de Investigaciones Reumatológicas; ${ }^{2}$ Renal Pathology, Hospital Central "Dr. Ignacio Morones Prieto", Universidad Autónoma de San Luis Potosí, San Luis Potosi, Mexico

Background: In 1983 Austin et al. informed a series of prognostic factors (including histology) associated with the development of renal failure in patients with lupus nephritis (LN). Differences in actual therapies may have different hazard ratios of renal failure than the described by Austin et al. ${ }^{1}$

Objectives: To evaluate histological factors associated with a decline in kidney function (DKF) in patients with SLE.

Methods: We evaluated all the patients in whom a kidney biopsy was performed. DKF was defined as a glomerular filtration rate (GFR) of less than $60 \mathrm{ml} / \mathrm{min} / \mathrm{m}^{2}$ in two determinations in the follow-up. Histology was graded according to Austin et al. ${ }^{1}$ (activity and chronicity) by a renal pathology specialist. Factors associated with the development of DKF were evaluated through Kaplan-Meier curves and Cox regression analysis (bivariate and multivariate).

Results: At this moment, we have followed 170 patients with LN and kidney biopsy, $130(76.5 \%)$ women, mean age at kidney biopsy was $29.7 \pm 13.2$ years classes of LN were: 71 patients $(41.8 \%)$ class IV, $30(17.6 \%)$ class V, $22(12.9 \%)$ class III/V, $19(11.2 \%)$ class IV/V, $16(9.4 \%)$ class III, and other classes 12 patients; 135 patients $(79.5 \%)$ have a minimum follow-up of 12 months. There were statistically significant differences in four groups of $L N$ : pure proliferative (classes III or IV), the combination with membranous (III/IV $\pm \mathrm{V}$ ), pure membranous (V) or other classes (Figure1).

Table 1. Factors associated with a DKF

\begin{tabular}{lcccc}
\hline Histological feature & $\begin{array}{c}\text { Bivariate } \\
\mathrm{HR}(\mathrm{Cl})\end{array}$ & $\begin{array}{c}\text { Bivariate } \\
\mathrm{p} \text {-value }\end{array}$ & $\begin{array}{c}\text { Multivariate } \\
\mathrm{HR}(\mathrm{Cl})\end{array}$ & $\begin{array}{c}\text { Multivariate } \\
\mathrm{p} \text {-value }\end{array}$ \\
\hline $\begin{array}{l}\text { Glomerular abnormalities } \\
\quad \text { Cellular proliferation }\end{array}$ & $1.01(0.83-1.22)$ & 0.920 & $\mathrm{NA}$ & $\mathrm{NA}$ \\
$\quad$ Karyorrhexis & $0.94(0.76-1.17)$ & 0.566 & $\mathrm{NA}$ & $\mathrm{NA}$ \\
$\quad$ Celular crescents & $1.09(0.96-1.22)$ & 0.179 & $0.95(0.82-1.10)$ & 0.501484 \\
$\quad$ Hyaline thrombi & $0.85(0.64-1.12)$ & 0.248 & $0.65(0.47-0.90)$ & 0.008837 \\
$\quad$ Leukocyte infiltration & $1.23(0.97-1.57)$ & 0.0848 & $1.03(0.77-1.40)$ & 0.815447 \\
$\quad$ Glomerular sclerosis & $1.79(1.41-2.26)$ & $<0.001$ & $1.67(1.23-2.25)$ & 0.000838 \\
$\quad$ Fibrous crescents & $1.71(1.27-2.29)$ & $<0.001$ & $1.55(1.11-2.16)$ & 0.009917 \\
$\quad$ Membranous & $0.50(0.30-0.85)$ & 0.0105 & $0.48(0.27-0.88)$ & 0.017001 \\
Tubulointerstitial abnormalities & & & & \\
$\quad$ Interstitial cell infiltration & $1.31(1.13-1.56)$ & $<0.001$ & $1.18(0.95-1.47)$ & 0.126099 \\
$\quad$ Interstitial fibrosis & $0.80(0.92-1.70)$ & 0.162 & $0.74(0.47-1.16)$ & 0.194012 \\
$\quad$ Tubular atrophy & $1.33(1.02-1.74)$ & 0.035 & $1.10(0.47-1.17)$ & 0.613154 \\
\hline
\end{tabular}

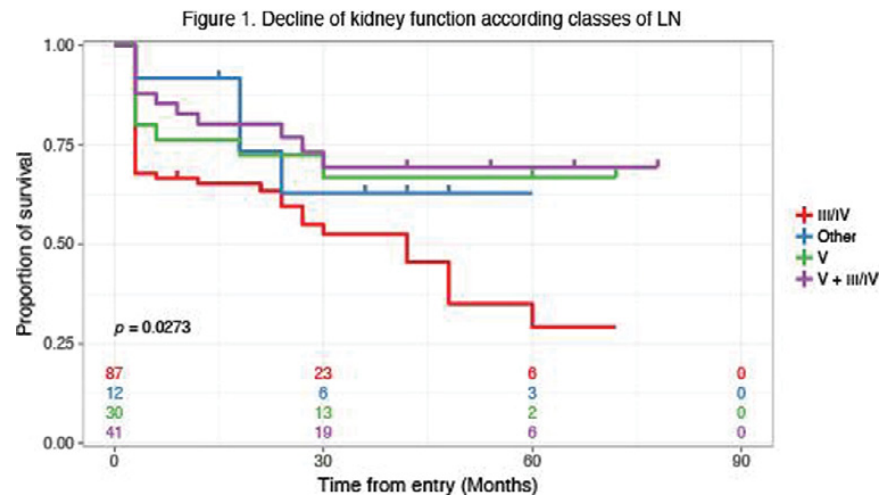


In the bivariate analysis, factors statistically significant associated with the development of DKF were: glomerular sclerosis, fibrous crescents, interstitial cell infiltration and tubular atrophy; having membranous component resulted as a "protector" factor for the development of DKF. The Cox regression model included all the factors with a $p$-value less than 0.25 in the bivariate analysis; independent factors associated with increased $\mathrm{HR}$ of DKF were glomerular sclerosis and fibrous crescents; however, hyaline thrombi and presence of membranous nephritis were associated with a decreased HR of DKF. (Table 1).

Conclusions: We describe factors associated with a DKF. We found that the proliferative $L N$ in combination with membranous have a better prognosis than pure proliferative LN. Our study could help to evaluate the effects of therapies in LN.

\section{References:}

[1] Austin HA, et al. Am J Med 1983;75:382-391.

Disclosure of Interest: None declared

DOI: 10.1136/annrheumdis-2017-eular.4156

\section{FRI0715 BEING A WOMAN AND HAVING KNEE OSTEOARTHRITIS INCREASES THE LIKELIHOOD OF COMORBIDITIES}

M. Herrero Barbero ${ }^{1}$, S. Gimenez ${ }^{2}$, J. Vergara $^{3}$, E. Viles I Lladó ${ }^{4}$, H. Martinez ${ }^{4}$, G. Rodríguez Roca ${ }^{5}$, L. Sánchez ${ }^{6}$, J.A. Díaz Muñoz ${ }^{7}$, J.F. Frias ${ }^{8}$, A. Castaño ${ }^{9}$ J.J. Jiménez Díaz ${ }^{10}$, Á. Rodríguez de Cossío ${ }^{11}$, R. Belenguer ${ }^{12}$, J.L. Llisterri ${ }^{13}$, J. Vergés Milano ${ }^{6,14}$ on behalf of EMARTRO. ${ }^{1}$ Plaça Francesc Macià 7 , Bioiberica, Barcelona; ${ }^{2}$ Unidad de Gestión Clínica el Limonar, Malaga; ${ }^{3}$ Centro de Salud Huercal, Almería; ${ }^{4}$ Bioiberica S.A., Barcelona; ${ }^{5}$ Centro de Salud la Puebla de Montalbán, Toledo; ${ }^{6}$ Bioiberica, Barcelona; ${ }^{7}$ Centro de Salud Ávila Rural, Ávila; ${ }^{8}$ Hospital Universitario Virgen de las Nieves, Granada; ${ }^{9}$ Centro de Salud Corella, Navarra; ${ }^{10}$ Centro de Salud Los Cubos, Burgos; ${ }^{11}$ Centro de Salud San Martin de la Vega, Madrid; ${ }^{12}$ Centro de Salud Algemesí; ${ }^{13}$ Centro de Salud Ingeniero Joaquín Belloch, Valencia; ${ }^{14}$ Osteoarthritis Fundation International, Barcelona, Spain

Background: Osteoarthritis $(O A)$ is the most prevalent joint disease and the leading cause of disability from 60 years onwards. In fact, $14,8 \%$ of the Spanish population has OA

Objectives: This study aimed to determine if there is a differential profile and greater comorbidity in women affected by symptomatic knee OA compared to a control group without OA.

Methods: The EMARTRO study was designed as an observational, multicenter, transversal study to compare probability of suffering a comorbidities based on presence of symptomatic knee OA visited by GPs. Sociodemographic, anthropometric, clinical parameters and clinical variables of interest were recorded. The probability of suffering comorbidities in each study group was estimated using the Odds Ratio estimation with conditioned logistic regression models. The HAD scale, the Goldberg health questionnaire were administered to patients and the concomitant medication was also registered. The comparison between groups was done using t-Student, Chi-square and Mann-Whitney.

Results: A total of 897 women were included with a mean (SD) age of $67.4(6.8)$ years.

Osteoarthritic women were obese and had a higher BMI compared with control group, 31.2 (5.5) vs 27.5 (4.3) ( $p<0.0001)$, respectively. Regarding blood pressure, no differences were found in the systolic BP $(p=0.0646)$ but in the diastolic, women with OA also had higher values, 77.9 (9.1) vs $75.8(8.9) \mathrm{mmHg}(p=0.0005)$.

In general terms, the presence of $\mathrm{OA}$ doubled the probability of having concomitant conditions with respect to controls [OR=2,220 $(95 \% \mathrm{Cl}: 1,449$ $3,400) p=0,0002]$. Likewise, women with syntomatic knee $O A$ were more likely to have hypertension [OR=1.697 $(95 \% \mathrm{Cl} 1.299-2.217), \mathrm{p}=0.0001]$, venous peripheral vascular disease $[\mathrm{OR}=2.148(95 \% \mathrm{Cl} 1.547-2.984), \mathrm{p}<0.0001]$ and gastroesophageal reflux (OR=1.890 (95\% Cl 1.297-2.754), $p=0.0009)$.

Regarding the mental health of the patients, according to the Goldberg scale, $41 \%$ of the patients with OA elicited psychopathology vs $17.8 \%$ in controls, $p<0.0001$. As for the HAD scale, there were more cases of anxiety $(p<0.0001)$ and depression in the OA women $(\mathrm{p}<0.0001)$.

The greater burden of physical and mental comorbidity in the OA patients was accompanied by a higher consumption of concomitant medications $(p<0.0001)$. Conclusions: The results of the present study indicate that in patients with knee OA, being female is a risk factor for the development of concomitant pathologies. Also, the increased likelihood of suffering from hypertension, venous peripheral vascular disease and gastroesophageal reflux should determine chronic medications for the treatment of osteoarthritis.

Disclosure of Interest: None declared

DOI: 10.1136/annrheumdis-2017-eular.3494

\section{FRI0716 RISK STRATIFICATION IN YOUNG PATIENTS WITH ACUTE MYOCARDIAL INFARCTION USING THE ADJUSTED GLOBAL ANTIPHOSPHOLIPID SYNDROME SCORE (AGAPSS)}

M. Radin ${ }^{1}$, K. Schreiber ${ }^{2}$, P. Costanzo ${ }^{3}$, I. Cecchi $^{1}$, D. Roccatello ${ }^{1}$ S. Baldovino ${ }^{1}$, M. Bazzan ${ }^{3}$, M. Cuadrado ${ }^{4}$, S. Sciascia ${ }^{1} .{ }^{1}$ Department of Clinical and Biological Sciences, Center of Research of Immunopathology and Rare Diseases- Coordinating Center of Piemonte and Valle d'Aosta Network for
Rare Diseases, Torino, Italy; ${ }^{2}$ Department of Thrombosis and Haemophilia, Guy's and St Thomas' Hospital, London, United Kingdom; ${ }^{3}$ S. Giovanni BoscoHospital, Torino, Italy; ${ }^{4}$ Guy's and St Thomas' NHS Foundation Trust, London, United Kingdom

Background: Young adults with acute myocardial infarction are a critical group to examine for the purpose of risk factors stratification and modification [1].

In the setting of underlying systemic autoimmune diseases, premature cardiovascular disease deserves even more attention in these conditions, such as antiphospholipid syndrome (APS), the most common acquired thrombophilia. Objectives: In this study we aimed to assess the clinical utility of the adjusted Global AntiphosPholipid Syndrome Score (aGAPSS)[2] for the risk stratification of acute myocardial infarction in a cohort of young APS patients with thrombotic events.

Methods: The analysis included 83 consecutive APS patients ( $<50$ years old) who presented with arterial or venous thromboembolic events. Data on cardiovascular risk factors and antiphospholipid antibodies (aPL) positivity were retrospectively collected. The aGAPSS was calculated for each patient by adding the points corresponding to the risk factors, based on a linear transformation derived from the $\beta$ regression coefficient as follows: 3 for hyperlipidaemia, 1 for arterial hypertension, 5 for aCL $\operatorname{lgG} / \operatorname{lgM}, 4$ for anti-b2 glycoprotein I lgG/lgM and 4 for LA. Results: Demographic, clinical and laboratory characteristics of the cohort are summarized in Table 1. Higher aGAPSS values were observed in patients with acute myocardial infarction when compared to the others [mean aGAPSS 11.9 (S.D. 4.15, range 4-18) Vs. (mean aGAPSS 9.2, S.D. 5.1, range 1-17); T test: $\mathrm{p}<0.05$ ]. Significantly higher aGAPSS values were also seen in patients with acute coronary syndrome compared to patients with a history of peripheral or cerebrovascular arterial thrombotic events [mean aGAPSS 11.9 (S.D. 4.15, range 4-18) Vs. (mean aGAPSS 6.7, S.D. 5.7, range 1-17); $T$ test: $P<0.005]$. When separating for cardiovascular risk factors and aPL positivity, hypercholesterolemia was significantly higher in the group that developed myocardial infarction compared with patients with a history of any thrombosis and patients with a history of peripheral or cerebrovascular arterial thrombotic events (Chi square test: $p<0.0001$ and $p<0.0001)$ and significantly higher rate of multiple positivity

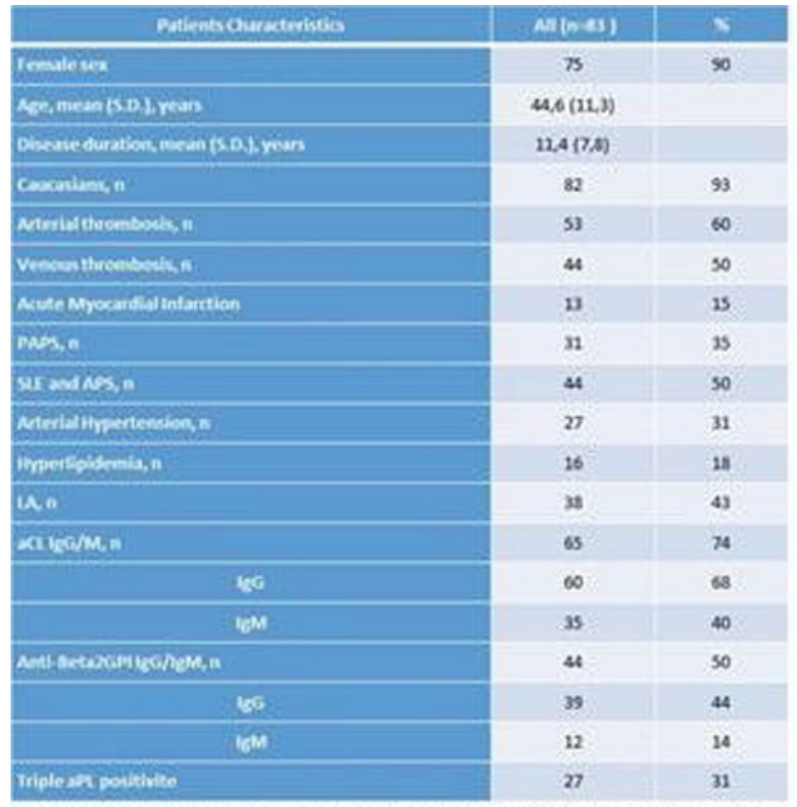

Table 1. Demographic, clinical and laboratory characteristics of the cohort

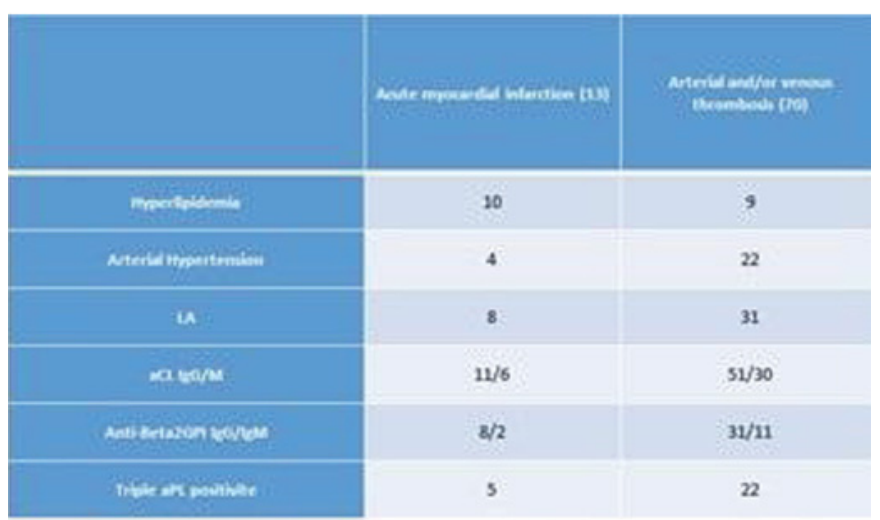

Table 2. Patients cardiovascular risk factors and aPL positivity between groups 